\title{
A ESCOLA FRANCISCANA: DE BOAVENTURA A OCKHAM
}

Luis Alberto De Boni*

SÍNTESE - Os franciscanos dos séculos XIII e XIV contaram entre seus membros com filósofos de renome. Procura-se, no presente trabalho, ver até que ponto pode-se falar de uma 'escola franciscana'. Para tanto é tomado o periodo que medeia entre Boaventura e Ockham, sendo examinados alguns dos principais temas debatidos durante a época.

PALAVRAS-CHAVE - Filosofia Medieval. Escola franciscana. Aristotelismo. Iuminação divina. Conhecimento de Deus. Matéria. Indivíduo.
ABSTRACT - Among thirteenth and fourteenthcentury Franciscans were counted some renowned philosphers. This article seeks to investigate to what extent one may speak of a "Franciscan school", within the period which spans from Bonaventure and Ockham, by examining some of the themes at that time.

KEY WORDS - Medieval Philosophy. Franciscan school. Aristotelianism. Divine ilumination. Knowledge of God. Matter. Individual.

No estudo da filosofia medieval, deparamo-nos com a expressão: Escola franciscana. ${ }^{1}$ Por definição baseada num critério exterior, diz-se então que se trata daquela corrente filosófica na qual se enquadram os diversos pensadores da ordem dos frades menores. Por este critério, aliás, podemos igualmente recordar que no capítulo geral da ordem, realizado em Strassburgo, em 1282, ante as turbulências provocadas pelo pensamento de Tomás de Aquino e pelas condenações de 1277, traçaram-se as linhas gerais a serem seguidas pelos mestres franciscanos. Se, porém, procurarmos defini-la por um critério interior, a partir da filosofia elaborada

Pontifícia Universidade Católica do Rio Grande do Sul - PuCrS.

A expressão é corrente, usada inclusive em títulos, como, entre outros: BETTONI, E. II problema della conoscibilità di Dio nella scuola francescana. Padova, 1950. BONAFEDE, G. La conoscenza del singolare nella scuola francescana del secolo XIII. Roma, 1922. HAMELIN, A.-M. L'école franciscaine, de ses débuts jusqu'à l'occamisme. Analecta medievalia Namurcensia, 12. 1961. ROHMER, J. "La théorie de l'abstraction dans l'école franciscaine". In: Archive d'histoire doctr. et litt. du Moyen Age, 3 (1928) 105-184. VAN DE WOESTYNE, Z. Scholae franciscanae aptatus cursus philosophicus. Malines, 2 v. 1921-25. VEUTHEY, L. "L'école franciscaine et la critique philosophique modeme". In: Études franciscaines, 18 (1936), p. 129-143, 257-266. Ainda há pouco J. A. Merino publicou a Histona de la Filosofia Franciscana (Madrid, 1993), onde apresenta "el aspecto genético-histórico de maestros que piensan y crean dentro de la corriente de una misma familia, en lo que tienen de común y, como no, de contradicción" (p. XIII).

\begin{tabular}{|l|l|l|l|l|l|}
\hline VERITAS & Porto Alegre & v. 45 & n. 3 & Setembro 2000 & p. $317-338$ \\
\hline
\end{tabular}


por seus principais expoentes, veremos que não é tarefa fácil dizer o que é precisamente o pensamento franciscano, qual o elo específico de ligação a agrupar homens tão diferentes entre si, como Boaventura e João Duns Scotus, Raimundo Lúlio e Guilherme de Ockham, Rogério Bacon e Pedro Olivi.

Pouco ajuda, no caso, o apelo para a analogia, procurando defini-la por uma contraposição com a escola dominicana. Mas também aqui as complicações são muitas. Acontece que Tomás de Aquino foi declarado doutor oficial da ordem dominicana em vários capítulos gerais da mesma, acontecidos em Milão (1278 e 1279), Paris (1286), Zaragoza (1309), Metz (1313), Londres (1314) e Bolonha (1315). Com isso, a ordem possuía um cânon e um autor e, então, a personalidade ímpar de Tomás de Aquino acabou por obnubilar nomes como os de Alberto Magno e Mestre Eckhart. Entre os franciscanos, ninguém desempenhou tal papel. Se o capítulo geral de 1282 houvesse declarado Boaventura modelo de pensador da ordem, a ser por todos seguido, sem dúvida, ele e Tomás de Aquino, contemporâneos, cada qual como cabeça de sua respectiva escola, representariam os dois paradigmas principais da ortodoxia filosófica medieval. Mas a história seguiu por caminhos diferentes; a ordem dos frades menores jamais escolheu alguém como seu pensador oficial; ela ainda deveria gerar outros nomes ilustres para a academia e conheceria um desenvolvimento de idéias filosóficas que só se encerraria cerca de 10 lustros após a morte de Boaventura. Embora os principais conhecedores do pensamento medieval, como E. Gilson ${ }^{2}$ e F. van Steenberghen ${ }^{3}$ (para só citar dois que polemizaram a respeito de Boaventura) reconheçam o significado e a importância deste autor, o primeiro dos medievais do auge da escolástica a elaborar um sistema filosófico pessoal acabado, não há dúvida que entre os frades menores houve uma sensivel evolução no que se refere à filosofia, em cujo término outros nomes acabaram por obnubilar o do antigo geral da ordem. Olivi, Duns Scotus e Ockham foram mais "filósofos" - e também mais "teólogos" - que Boaventura; no passado houve a escola scotista e a nominalista, enquanto uma escola bonaventurina jamais se constituiu; e ainda hoje aqueles suscitam maior interesse nos meios acadêmicos que o antigo geral da ordem.

Entretanto, constata-se que há certos temas, certas idéias recorrentes dentro do grupo. Se, pois, por um lado, há um distanciamento crescente no decorrer dos anos, fazendo com que muito do que se produziu entre 1240 e 1270 pareça retórica, quando não peça de museu, por outro lado, percebe-se que sob as aparências de diversidade perpassa um filão de idéias, de soluções, de modos de trabalhar que, devidamente adaptados, fazem parte de um patrimônio comum.

Atenho-me aqui a alguns pontos paradigmáticos de ruptura e a outros de continuidade, tentando, através deles, esclarecer em parte o que aconteceu na vida intelectual franciscana nos anos 70 que medeiam entre o início da produção teológica de Boaventura em Paris e a interrupção das atividades acadêmicas de Ockham em Oxford.

GILSON, E. La philosophie de saint Bonaventure. Paris, 1924.

VAN STEENBERGHEN, F. La philosophie au XIII siècle. Louvain-Paris, 1966. O texto vem citado pela edição alemã: Die Philosophie im 13. Jahrhundert. München/Paderborn/Wien, 1977, p. 186-253. 


\section{Um momento de ruptura: o tropeço em Aristóteles}

A meu modo de ver, o que leva esta escola por um longo caminho evolutivo, distinguindo-a assim da dominicana, é a opção filosófica inicial de Boaventura mantendo-se no caminho aberto por Alexandre de Hales e João de la Rochelle - pela tradição neoplatônico-agostiniana, valendo-se de Aristóteles de forma secundária. 0 contrário aconteceu com os dominicanos: nos passos de Alberto Magno, Tomás de Aquino, de uma só vez, fez a recepção de Aristóteles em seu sistema e as resistências intemas da ordem, num primeiro momento, esvairam-se de todo antes do final do século XIII. Dentro do mundo franciscano, a recepção de Aristóteles haverá de dar-se aos poucos, por isso mesmo de forma muito mais crítica: a praesumptio iuris em favor da tradição da ordem (por vezes mais aviceniana ou avincebroniana que agostiniana) exigia cuidados redobrados quando, ao surgirem divergências entre a tradição e as idéias peripatéticas, parecesse de melhor alvitre optar por estas últimas.

As edições críticas das obras de Boaventura, Scotus e Ockham permitem que se constate esta evolução. Já o simples manuseio dos índices mostram uma primeira diferença: enquanto, para Boaventura, Agostinho é o autor mais citado, seguido por Aristóteles, e ocupando Dionísio o terceiro lugar, para Scotus e Ockham invertem-se as preferências, cabendo o primado a Aristóteles, seguido por Agostinho, enquanto Dionísio desaparece quase por completo, abrindo-se espaço, porém, para Avicena e Averróis. Boaventura, fazendo eco a Agostinho, quando diz que Platão "brilhou com glória excelente, que obscureceu a dos demais", ${ }^{4}$ declara abertamente sua preferência por Platão, porque na filosofia deste há espaço para as idéias e para o transcendental, o que teria sido perdido por Aristóteles. ${ }^{5}$ Scotus e Ockham, pelo contrário, estão muito mais perto de Tomás de Aquino, que relega Platão a um plano secundário e que, ao tentar fazer um histórico do desenvolvimento de certos temas dentro da filosofia, mostra como Aristóteles apresentou uma solução bem mais satisfatónia, porque comigiu Platão. ${ }^{6}$

4 "Sed inter discipulos Socratis, non quidem immerito, excellentissima gloria claruit, qui omnino caeteras obscuraret, Plato" (VIII De civitate Dei, c. 4, PL 41, 227).

5 Cfr., por exemplo: "Nam aliqui negavenunt in ipsa [causa prima] esse exemplaria rerum; quorum princeps videtur fuisse Aristoteles, qui et in principio Metaphysicae et in fine et in multis aliis locis exsecratur ideas Platonis [...]. Unde illas ideas praecipuus impugnat Aristoteles et in Ethicis, ubi dicit quod summum bonum non potest esse idea [...]. Ex hoc errore sequitur alius erros, scilicet quod Deus non habet praescientiam nec providentiam, ex quo non habet rationes rerum in se, per quas cognoscat" (In Hexaëmeron, coll. VI: V, 360s).

Cfr. p. ex.: "Plato enim posuit omnium rerum species separatas, et quod ab eis individua denominantur, quasi species separatas participando [...]. Et quamvis haec opinio irrationabilis videatur ut Aristoteles multipliciter probat..." (ST I, 6, 4 in corp.) "Deus non intelligit res secundum ideam extra se existentem. Et sic etiam Aristoteles improbat opinionem Platonis de ideis, secundum quod ponebat eas per se existentes, non in intellectu" (ibid. I, 15, 1 ad 1um). "Plato enim posuit formas quae sunt in materia corporali, derivari a formis sine materia subsistentibus [...] Sed, sicut probat Aristoteles in VII Metaphysicorum, id quod proprie fit est compositum" (Ibid. I, 65, 4 in corp.). "Plato autem distinxit inter intellectum et sensum. Utrumque tamen attribuit principio incorporeo [...] Sed Aristoteles libro III De anima posuit quod solum intelligere, inter opera animae, sine organo corporeo exercetur" (Ibid. I, 75, 3 in corp.). "...Plato [..] posuit diversas animas esse in corpore uno [...]. Quam quidem opinionem Aristoteles reprobat..." (Ibid. I, 76, 3, in corp.). 
Boaventura, que estudou lógica na Faculdade de Artes, contentou-se com o que nela apreendeu, valendo-se da lógica como de um instrumento de trabalho. Das demais obras de Aristóteles, que cita, mostra ter um bom conhecimento, mas que de maneira nenhuma dá-lhe segurança nos debates, o que o leva, nas collationes pronunciadas no fim da vida, a encarar o filósofo grego do ponto de vista teológico, não descendo jamais ao debate filosófico. Não legou à posteridade nenhum comentário ou exposição sobre ele, não porque para tanto lhe houvesse faltado tempo, mas porque não fazia parte de seu projeto de trabalho dedicar-se à exegese do pensamento de um pagão, para quem, logicamente, o tema central da redenção por Cristo era desconhecido.

Entretanto, no mundo acadêmico do século XIII, era de fundamental importância reaprender Aristóteles.? Pela primeira vę o saber ocidental defrontava-se com um sistema filosófico completo, de uma coerência interna que não podia ser ignorada, mas que, por ser novo, precisava ser digerido, assimilado pelos pensadores da época. Rogério Bacon, Alberto Magno e Tomás de Aquino perceberam muito bem esta nova realidade: ler, esmiuçar, debater a obra aristotélica não constituía mero exercício acadêmico: era condição de possibilidade de construção de um novo saber, que se implantava de modo irreversível nas universidades. Por isso, já nos últimos anos de sua não tão longa existência, na qualidade de professor da faculdade de teologia, Tomás empenha-se em comentar os principais textos do corpus anistotelicum, na convicção de que, sem passar pelo crivo do Estagirita, o trabalho acadêmico corria o risco de rodar à semelhança do moinho vazio.

Dentro deste contexto, a posição de Boaventura, em toda sua pureza, acaba ficando isolada em poucos anos, pois mesmo seus seguidores mais fiéis, influenciados de um lado pela tradição oxfordiana da ordem e desafiados, por outro, pelo modelo albertino-tomista, sentem-se também compelidos ao aprofundamento do estudo de Aristóteles. R. Grosseteste e R. Bacon já haviam escrito comentários literais, que de início não servem como modelo, atendo-se os frades a pequenos tratados. Assim, por exemplo, João Peckham (1220-1292), o principal oponente de Tomás de Aquino, quando da última estada deste em Paris, escreve: Perspectiva communis, De animalibus, Tractatus de perspectiva et inide, Tractatus de numeris, Tractatus Sphaerae, Theoria planetarum, Tractatus de anima. ${ }^{8}$ Vários outros frades da mesma época, todos eles professores de teologia, como Rogério Marston, Mateus de Acquasparta e Gonçalo de Espanha, envolvidos nas grandes disputas acadêmicas antiaverroístas - e por que não antitomistas? - julgam ser necessário dedicar-se às Quaestiones de anima. Com isso, estava aberto o caminho para que Scotus, na virada do século, se lançasse a comentar a obra aristotélica.

Se, porém, olharmos para os textos que Scotus e Ockham comentaram, e os aproximarmos daqueles de Tomás de Aquino, constataremos uma diferença sintomática. Tomás, é mais do que evidente, relegou os textos lógicos a um segundo 1948).
} 
plano, voltando sua preferência para as obras de cunho mais filosófico (entendendo-se aqui filosofia em sua tríplice divisão tradicional: metafísica, física e ética). Da lógica aristotélica comentou tão somente In libros posteriorum analyticonum expositio, e In libros perihermeneias expositio (até a lectio 2 do livro II). Já Scotus trabalha durante anos as Quaestiones super libros Metaphysicorum Aristotelis (os nove primeiros livros), que acabam de ser publicadas'. Também atribui-se a ele, ao menos em suas linhas gerais, as Quaestiones super libros Aristotelis de Anima, cuja autoria, porém, deve ser de Antônio André. No mais, seus comentários e tratados voltam-se para as obras lógicas: Super universalia Porphyrii; In librum Praedicamentorum quaestiones; Quaestiones in primum et secundum librum Praedicamentorum; In duos libros Perihermeneias; In libros Elenchorum Aristotelis quaestiones. Percebe-se também que diversos textos atribuídos erroneamente a ele ou são comentários a Aristóteles, ou trabalhos referentes à lógica e à linguagem, como a Gramática especulativa, cujo autor é Tomás de Erfurt. ${ }^{10}$ Isto, a meu modo de ver, indica que, para os contemporâneos, o nome de Scotus encontravase intimamente ligado com o conhecimento da lógica aristotélica. Aliás, Ockham, ao tratar do problema da existência de Deus, debate longamente com Scotus, cujos textos reproduz, e não deixa de observar que estava discutindo com alguém que muito entendia de lógica. ${ }^{11}$

Algo semelhante acontece com Ockham. Há nele um interesse pela Física da qual legou-nos: Expositio in libros physicorum Aristotelis, Brevis summa libri physicorum e Quaestiones in libros physiconum. Os demais comentários são todos sobre a lógica: Expositio in libros artis logicae prooemium; Expositio in librum Porphyrii de praedicamentis; Expositio in librum praedicamentorum Aristotelis; Expositio in librum perihermeneias Aristotelis; Expositio super libros elenchorum. Além disso, já ao concluir sua breve vida acadêmica como teólogo, produziu o mais importante texto medieval sobre lógica: a Summa totius logicae (entre as obras duvidosas a ele atribuídas, há também o Tractatus minor e o Elementarium logicae: ambos teriam sido redigidos no exilio, em München).

Cabe, sem dúvida, a objeção de que os comentários lógicos de Scotus e Ockham (com exceção da Summa ockhamiana), foram obras do início da carreira acadêmica, enquanto os grandes comentários de Tomás foram redigidos no fim da vida. A resposta, que começa com a observação de que a carreira de Scotus e Ockham só teve início, observa que a objeção não invalida a afirmação de que há uma notável diferença de interesse entre os três pensadores. Tomás também foi aluno da faculdade de artes e sua competência no domínio da lógica aristotélica dispensa

9 Cfr. Johannis Duns Scoti. Quaestiones super libros metaphysicorum Aristotelis (Opera Philosophica, III-IV). Saint Bonaventure, 1997.

10 Além da Grammatica speculativa, C. Balic (op. cit. p. 33s.) enumera: In lib. I et II Priorum Analyticonum quaestiones, Quaestiones in lib. I et II Posteniorum Analyticonum, Dulcissima expositio et quaestiones in octo libros Physicorum, Meteorologicorum libri 4, Quaestiones disputatae de rerum pnincipio, De cognitione Dei, Quaestiones miscellaneae de formalitatibus, In duodecim libros Meta11 physiconum expositio, Conclusiones utilissimae in XII lib. Metaphysicorum, De perfectione statuum. "Nec credo aliter istum Doctorem [Scotum] sensisse propter magnam notitiam quam habuit de logica" (Ockham. Ord. I, d. 2, q. 10; OTh 2, p. 344; cf. ibid. q. 6, p. 161). 
comentários; no entanto, parece estar satisfeito com o que lhe foi ensinado no curso. Já os dois franciscanos, vivendo algumas décadas após, encontram problemas exatamente lá onde Tomás não julgou necessário maior aprofundamento: na área da lógica e da linguagem, e foi na qualidade de teólogos que redigiram seus textos. De fato, Duns Scotus, de quem ainda não temos a edição crítica das obras lógicas, para melhor datar-lhes a composição, deve ter redigido seus comentários já em Paris, no último lustro do século, durante os estudos de teologia. ${ }^{12}$ Quanto a Ockham, como demonstra o prefácio da edição crítica, as expositiones foram redigidas após o Comentário às Sentenças, portanto durante o curso de teologia, num momento em que o autor já havia concluído os estudos regulares e, dentro dos costumes da ordem, se preparava para ocupar o posto de magister actu regens. ${ }^{13}$

Poderemos tentar uma explicação para esta diferença de interesses, dizendo que naquele tempo esboçava-se uma divisão paradigmática entre algo assim como analíticos e continentais? - Este chavão, a meu modo de ver, se aplicado à Idade Média, leva a mal-entendidos piores do que quando aplicado à filosofia contemporânea. Os três autores entenderam-se como filósofos e, mais ainda, como teólogos. Todos eles tiveram uma aguda percepção da época em que viviam e do que significava o trabalho filosófico naquele instante. A maior preocupação com lógica e filosofia da linguagem, por parte de Scotus e Ockham, não aconteceu por preconizarem eles uma separação de campos na filosofia, mas porque perceberam que, naquele momento de avaliação crítica do aristotelismo, as questões de lógica e de linguagem extrapolavam a função de simples instrumento de trabalho. A recepção do passado filosófico, para se manter aberta, para não perder a capacidade de sempre elaborar novas perguntas, precisava tanto de uma rigorosa análise lógica, como de estudos acurados sobre os diversos níveis e significados de linguagem nos quais o discurso estava sendo elaborado. Os dois pensadores, por sinal não-continentais de nascimento, não foram antecessores de futuras teorias sobre cisões paradigmáticas, mas espíritos sutis e atilados, capazes de perceber que uma filosofia consistente, em sua época (o que significava também uma teologia à altura do tempo), precisava levar para seu interior, como constitutivo do discurso, aquilo que outros tomavam mais como ferramenta de trabalho. Quando, há três décadas, Teodoro de Andrés propôs ler a obra de Ockham como uma filosofia da linguagem, ${ }^{14}$ estava percebendo com rara felicidade que, para a compreensão do Venerabilis Inceptor, não basta submeter-lhe o discurso ao crivo da crítica lógico-lingüística: é preciso, principalmente, incorporar a lógica e a linguagem ao próprio conteúdo do filosofar.

12 Cfr. CALlebaut, A. "Le séjour du bx. Jean Duns Scot à Paris. Son millieu universitaire". In: La France Franciscaine 12 (1929) p. 353-373; BALIC, C. John Duns Scotus - Some Reflexions on the Occasion of the Seventh Centenary of his Birth. Roma, 1966, p. 37-40.

13

Os editores supöem como data mais provável das diversas expositiones os anos de 1321 e 1322, tendo como local de composição o estudo dos frades franciscanos, em Londres, e não a universidade de Oxford (Opera Philosophica, vol. II. St. Bonaventure, 1978, p. 14s.).

14 ANDRÉS, T. de. El nominalismo de Ockham como filosofia del linguage. Madrid, 1969. Cfr. tb. TODISCO, O. Duns Scoto e Guglielmo d'Occam. Dall'ontologia alla filosofia del linguaggio. Cassino, 1989. 


\section{Outro momento de ruptura: iluminação divina e conhecimento humano}

Apesar das divergências entre os propugnadores da teoria da iluminação, podese resumi-la como a defesa de um concurso especial de Deus, sob a forma de uma luz, que manifesta a verdade e estabelece o espírito na certeza. ${ }^{15} \mathrm{O}$ problema encontra suas primeiras elaborações na obra de Roberto Grosseteste, sendo desenvolvido por Gilberto de Toumai e retomado posteriormente, com as devidas nuanças, por Boaventura e diversos outros, quase todos pertencentes à escola franciscana. A inspiração original, é evidente, possui caráter agostiniano: por si mesmo, o espírito humano não pode chegar à certeza, pois tanto o que conhece, como o que faz conhecer, como o que é conhecido são mutáveis. Portanto, somente a luz divina pode oferecer a garantia de certeza do conhecimento. Em seu pequeno texto De veritate, Grosseteste elabora o que C. Berubé chama de "catecismo filosófico da teoria da iluminação", ao dizer, no núcleo central: "Como, porém, a conformidade de algo com algo pode ser percebida, a não ser que seja percebido aquele com o qual ela é conforme? Ou a retidão da coisa, como pode ser conhecida como retidão, se não existe em si a retidão, a não ser em sua regra que é reta em si mesma, e segundo a qual a própria coisa é retificada? Tal regra nada mais é que a razão etema da coisa na mente divina. Ou como se pode conhecer que a coisa é assim como deve ser, a não ser que se veja a razão segundo a qual assim deve ser? ${ }^{n 16}$

Boaventura recebe de seus antecessores esta teoria e a reelabora, cioso em evitar qualquer forma de ontologismo. Conhecedor de teoria do conhecimento de Aristóteles, não ignora o caráter natural da certeza por parte tanto da sensibilidade como da inteligência, mas delimita-lhes o alcance, pois sem a influência da razão eterna, enquanto ratio regulans et motiva, não pode haver a certeza plena do conhecimento. ${ }^{17}$ Tal influência não se encontra a nível consciente, mas é percebida pela inteligência ao termo de uma análise reflexiva, quando então compreende que sem a iluminação divina não é possivel explicar o conhecimento certo que o homem forma de si, do mundo e de Deus. Há, pois, uma ação direta de Deus sobre o intelecto humano, mas tal ação não é percebida, a não ser por um processo reflexivo. Não se trata, pois, do auxílio geral de Deus a todo o ser criado, nem da graça da visão beatífica, mas de algo intermediário, não percebido de imediato, mas sem o que nenhuma certeza é possivel.

15 Cfr. BÉRUBÉ, C. "Olivi: Critique de Bonaventure et d'Henri de Gand". In: Id. De l'homme à Dieu selon Duns Scot, Henri de Gand e Olivi. Roma, 1983. p. 18-80.

16

"Quomodo enim conspici posset conformitas alicuius ad aliquid, nisi conspecto etiam illo cui est conforme? Aut rectitudo rei, quomodo cognoscitur quia rectitudo est, cum non sit per se rectitudo nisi in regula sua quae secundum se recta est, et secundum quam ipsa res est rectificata? Quae regula non est aliud quam ratio rei aeterna in mente divina. Aut qualiter cognoscetur quod res est ut esse debet, nisi videatur ratio secundum quam sic esse debet? [...]" (De veritate, p. 137, apud BERUBE, C. op. cit., p. 27).

17 " $[. .$.$] ad certitudinalem cognitionem necessario requiritur ratio aeterna ut regulans et ratio motiva,$ non quidem ut sola et in sua omnimoda claritate, sed com ratione creata, et ut ex parte a nobis contuita secundum statum viae" (Quaestiones disputatae de scientia Christi, 4. Opera omnia, v. V, p. 23). 
O principal herdeiro de Boaventura, na questão da iluminação divina e do objeto primeiro do conhecimento humano, foi o padre secular Henrique de Gand. Durante seu longo magistério em Paris (de 1276 a 1292), reelaborou o pensamento dos antecessores por causa dos avanços do aristotelismo, Observa que o homem pode chegar ao conhecimento da verdade (ou melhor, do verdadeiro) por sua própria inteligência, mas não pode chegar ao conhecimento da verdade em si (da veritas sincera), o que só acontece por uma iluminação divina, que não é objeto, mas causa do conhecimento. Distinguindo, então, entre o conhecimento em sentido amplo, baseado na conformidade entre o intelecto e a espécie (imagem) criada, e o conhecimento em sentido estrito, aceita para aquele as formulações correntes da filosofia aristotélica, mas exige para este que exista o conhecimento da relação entre a coisa e seu exemplar eterno, pois só assim, pensa ele, pode haver estabilidade, infalibilidade e clareza. Com isso, porém, acaba colocando como modelo de certeza aquele proposto pelos acadêmicos, que inclui como condição não apenas o conhecimento livre de dúvida e de erro, mas também, e acima de tudo, a exigência de que aquele que conhece tenha provas, graças às quais seja capaz de distinguir, sem sombra de dúvida, entre a verdade e a aparência de verdade. Além disso, colocando como correlatos e quase que sinônimos os conceitos de ens simpliciter de Avicena (pelo qual se afirma que nas noções universais de ente, de uno, de bom, etc. o homem pode perceber o ente simplesmente) e 0 conceito agostiniano de ens simpliciter et subsistens (segundo o qual a referência aos conceitos universalíssimos implica uma referência a Deus, o ente de todos os entes, o bem simplesmente de todo o bem), acaba por afirmar que Deus, embora seja o último conhecido na ordem racional, é contudo o primeiro conhecido por um conhecimento natural que foge à nossa consciência, mas que se encontra claramente ensinado por Agostinho. ${ }^{18}$

Coube ao franciscano provençal, Pedro João Olivi, empreender a crítica às posições de Henrique de Gand. ${ }^{19}$ Observa ele que é inútil tentar elaborar uma prova sobre a existência de Deus, se Deus é visto imediatamente ou se é a causa de todo o conhecimento. Assim, embora muitos argumentos de Henrique e dos demais seguidores da iluminação divina possam ser reinterpretados, não é possivel aceitar os argumentos agostinianos da existência de Deus pela iluminação e pela identificação da verdade com Deus. $O$ que se pode reter da iluminação divina é o que também Tomás de Aquino estaria disposto a conceder: que Deus coopera com a atividade da inteligência como convém a uma natureza intelectual, para a qual ele é o primeiro princípio e o exemplar. Mas esta cooperação não significa nem a redução do intelecto humano à mera passividade, nem a negação da liberdade divina, colocando-a necessariamente em função do conhecimento humano. Os limites de nosso conhecimento, para Olivi, são bem mais modestos: nós não possuímos certeza semelhante à de alguém que pudesse ver as coisas à luz divina,

${ }_{19}^{18}$ Cfr. BERUBÉ, C., op. cit., p. 41-54.

Ibid., p. 58-72. 
mas somos capazes de, pelas evidências desenvolvidas a partir dos primeiros princípios, obter aquela certeza que os objetos oferecem enquanto estão em nossa mente, e não na mutabilidade extramental. Com isto está praticamente concluída a crítica à teoria da iluminação. Olivi mostra como esta teoria, para salvar a importância divina na certeza do conhecimento humano, acaba por sacrificar a transcendência de Deus.

Na mesma linha, e retomando-lhe as conclusões, Scotus afirma que o apelo à iluminação divina, a fim de fundamentar a certeza do conhecimento humano, acaba caindo no vazio, pois a conformidade com o exemplar incriado só pode ser conhecida se o próprio exemplar for conhecido, ${ }^{20}$ mas então o exemplar eterno para poder ser causa do conhecimento, deveria também ser conhecido. Se, porém, segundo Henrique, não se conhece o exemplar divino, então, conclui Scotus, também não se tem conhecimento da veritas sincera e, assim, os argumentos de Henrique não concluem com Agostinho, nem com a verdadeira razão, mas com os acadêmicos. ${ }^{21}$ De sua parte Scotus, fiel a Aristóteles, afirma que, pela razão natural, isto é pela espécie (imagem) criada, sem qualquer iluminação, sob as devidas condições podemos ter certeza a) dos primeiros princípios e das conclusões que dele derivam; b) do conhecimento sensivel, e c) de nossos atos internos.

Quando Ockham redigiu sua obra, a teoria da iluminação divina já saíra totalmente de cena. A crítica de Olivi e Scotus fora arrasadora, dispensando-o de arrolar novamente argumentos, ou de perguntar-se a respeito dela.

\section{Mais um momento de ruptura: o conhecimento de Deus}

A pergunta sobre o que o homem pode saber, pela simples razão, a respeito da existência e dos atributos de Deus é tema comum a todos os medievais. Teólogos, homens da Igreja, convictos de sua fé cristã, procuram a explicação racional para aquilo em que crêem e perguntam-se sobre os limites da razão no conhecimento da fé. No decorrer dos anos percebe-se que o rigor metodológico leva a limitar sempre mais claramente $o$ alcance da razão humana ao falar a respeito de Deus. A convicção de Anselmo, ao tratar, no Monologion, racionalmente, de grande parte das verdades da fé não é compartilhada pelos teólogos do século XIII e XIV, leitores e admiradores confessos do abade de Le Bec.

Sem dúvida, o texto mais conhecido sobre a existência de Deus é o de Tomás de Aquino na Suma Teológica, ao mostrar que por cinco vias, todas elas partindo da contingência do sensivel, podemos chegar à noção de um ser primeiro, não movido, incausado, necessário, perfeito e ordenador do universo.

Ibid. n. 218 (Vat. III, p. 132): "[...] istae rationes [Henrici] non sunt rationes fundamentales alicuius opinionis verae, nec secundum intentionem Augustini, sed sunt pro opinionem academicorum." Observe-se que Scotus, na trilha de Olivi, evita a critica aberta à "autoridade" de Agostinho, de quem procura explicar a "intentionem", visto que as palavras concordam com as de Henrique. 
Entre os franciscanos, os caminhos a respeito da demonstrabilidade da existência de Deus são bem mais sinuosos, e nem sempre complementares. Pressupostos diferentes e ambiente filosófico diverso levaram logicamente a conclusões diversas. Por vezes os estudiosos tendem a minimizar estas diferenças, ${ }^{22}$ acentuando os traços comuns, mas elas não se deixam reduzir tão facilmente.

Boaventura, como foi muito bem observado, não demonstra propriamente a existência de Deus: ele a mostra. ${ }^{23}$ Tendo, na esteira de Alexandre de Hales, tomado como fundamental em seu pensamento a doutrina das idéias em Deus e tendo, como vimos, complementado sua gnosiologia com a teoria da iluminação, acabou por concluir o arcabouço teónico de seu sistema com a também agostiniana ontologia do exemplarismo: 0 discurso humano, o conhecimento humano, refere-se às coisas, mas estas referem-se à idéia que delas existe em Deus. Assim como o Filho é expressão do Pai intra-trinitatem, de tal modo que, conhecendo o Filho, o Pai conhece a si mesmo, assim também, as coisas são, em sua realidade maior, a expressão da divindade ad extram, de tal forma que, pelo conhecimento das coisas, chega-se com facilidade ao conhecimento de Deus, de quem, a seu modo, todas elas são vestígio, imagem ou semelhança. As coisas são, portanto, uma manifestação de Deus acessivel a qualquer inteligência humana, e ao considerá-las o homem percebe que são mais verdadeiras na idéia que Deus possui delas do que na realidade exterior em que são percebidas.

Neste contexto, as provas racionais da existência de Deus perdem muito de seu significado, "são antes uns exercícios intelectuais que razões fornecedoras de evidência e manifestadoras do verdadeiro que foi provado". ${ }^{24}$ Tais provas agrupamse em três categorias. A primeira delas, que goza de sua preferência, é a de caráter psicológico, de sabor agostiniano: a notícia de Deus é naturalmente inata na alma humana. Basta ao homem olhar para seu interior, e nele haverá de descobrir a existência da idéia de Deus, ou melhor, ao conhecer-se a si mesma, a alma conhece a Deus. ${ }^{25} \mathrm{~A}$ aspiração à verdade e à felicidade é algo de inato no homem e que, como ele bem percebe, não the vem de fora, mas do mais fundo de sua interioridade, a modo de um desejo, de uma noção e de uma recordação daquilo de que é imagem. A segunda via, de cunho aristotélico parte da existência da realidade exterior finita para concluir pela existência de Deus. São dez caminhos indicados, dentro de um esquema que em muito se assemelha, exteriormente, ao tomista, mas que na realidade não dão tanta importância ao ponto de partida do

22 Parece-nos que é o caso de BETTONI, E. Il problema della conoscibilità di Dio... Principalmente na conclusão da obra (p. 394-406), a posição de frei Bettoni, a cujos trabalhos muito devemos, não pode ser de todo aceita, quando pretende ver uma linha de desenvolvimento quase sem rupturas entre Alexandre de Hales, Boaventura e Duns Scotus.

23

24 SARANYANA, J. Historia de la filosofia medieval. 2. ed. Pamplona, 1989. p. 219.

"potius sunt quaedam exercitationes intellectuales quam rationes dantes evidentiam e manifestantes ipsum verum probatum" (Quaestiones disp. de myst. Trinitatis, 1, 1: ad 12 un. Opera omnia, v. V, p. 51).

25

"Inserta est animae rationali notitia sui, eo quod anima sibi presens est et seipsa cognoscibilis; sed Deus praesentissimus est ipsi animae et se ipso cognoscibilis: ergo inserta est ipsi animae notitia Dei sui" (ibid. I, 1, v. V, p. 46). 
sensível, acentuando mais o fato de que toda a realidade aponta para Deus. ${ }^{26}$ Enfim, num terceiro caminho, Boaventura assume, reelaborando, o argumento de santo Anselmo sobre a necessidade da existência daquele ser do qual nada se pode pensar maior. ${ }^{27}$

Quanto aos atributos divinos, Boaventura segue a tradição, atribuindo a Deus todas as perfeições na simplicidade absoluta do ser.

Entre os seguidores de Boaventura, como João Peckham, Guilherme de la Mare, Mateus de Acquasparta e Rogério Marston, as nuanças do trabalho filosófico não modificam o que foi herdado do mestre. Algo idêntico acontece com diversos pensadores da geração posterior, como Guilherme de la Mare e Pedro Auréolo. 0 próprio Pedro João Olivi, mesmo tecendo críticas a formulações anteriores, mantém-se na linha bonaventurina no tocante às provas de Deus e aos atributos dele. Mas já surgem vozes destoantes: Ricardo de Mediavilla, por exemplo, ao recusar em gnosiologia toda a espécie de iluminação, e ao negar, portanto, qualquer idéia inata de Deus, recusa, logicamente, o argumento de tipo anselmiano sobre a existência de Deus, por não ser um argumento a posteriori.

A guinada histórica no meio franciscano foi dada por Duns Scotus, que declaradamente deseja fazer um estudo puramente filosófico a respeito do que a inteligência humana pode saber a respeito. ${ }^{28}$ Retomando por diversas vezes a questão das provas da existência de Deus, o frade escocês, ao invés de construir sua argumentação a partir da efetividade, prefere construí-la a partir da possibilidade. ${ }^{20}$ Concordando com Ricardo de Mediavilla e com Tomás de Aquino, só julga válida a prova a posteriori (por isso, o argumento anselmiano só pode ser aceito se submetido a uma 'coloração'), mas ao invés de várias provas, elabora apenas uma, baseada no tríplice primado que julga caber ao primeiro princípio: o da causalidade, o da finalidade e o da eminência. A este primeiro princípio, que é único e pessoal, compete a atividade espiritual de conhecer e querer, a simplicidade absoluta e a infinidade intensiva, mas é de parecer que não se pode, pela simples razão, atribuir a ele a onipotência, tal como o entendem os católicos, ao afirmarem que Deus pode fazer por si mesmo tudo aquilo que produz através de causas segundas. $\mathrm{O}$ mesmo se diga quanto à onipresença, à justiça, à misericórdia e à providência. $^{30}$

\footnotetext{
Ibid., I, 1, n. 11-20, p. 46-47.

Ibid., I, 1, in corp., n. 21-29, p. 47-48. Cfr. I Sent. I, d. 8, p. 1, a. 1, q. 2. concl. v. I, p. 154-155.

"Adjuva me, domine, inquirentem ad quantum cognitionem de vero esse, quod tu es, possit pertingere nostra ratio naturalis ab ente, quod de te praedicasti, inchoando" (DUNS SCOTUS. Tractatus de primo principio. ed. W. Kluxen, Darmstadt, 1974, p. 2).

"In hac conclusione [...] possem proponere actum sic: Aliqua natura est efficiens, quia aliqua est effecta, quia aliqua incipit esse, quia aliqua est terminus motus et contingens. Sed malo de possibili proponere conclusiones et praemissas. Illis quippe de actu concessis, istae de possibili conceduntur, non e converso. Illae etiam de actu sunt contingentes, licet satis manifestae, istae de possibili sunt necessariae" (Ibid., p. 32ss.).

"Praeter praedicta, de te a philosophis praedicta, saepe Catholici te laudant omnipotentem, immensum, ubique praesentem, iustum et misericordem, cunctis creaturis et specialiter intellectualibus providentem [...]" (Ibid., p. 126).
}

30 
A posição de Scotus, para ser corretamente compreendida, precisa ser reportada ao que afirmamos acima sobre a aceitação de Aristóteles no meio franciscano. Quando o pensador pagão tornou-se, também para os frades menores, o filósofo por excelência, ficou evidente que um modelo neoplatônico-agostiniano de argumentação estava excluído, e com ele as provas a priori da existência de Deus, bem como as baseadas no inatismo das idéias. Ao mesmo tempo, o rigor filosófico passou a distinguir sempre mais entre os atributos que a filosofia atribui a Deus e os que só podem ser atribuídos pela fé. Assim, rompia-se o modelo de discurso único sobre Deus, abrindo-se um espaço bem delimitado para o discurso dos filósofos, bem diferente do discurso dos teólogos.

As idéias de Scotus foram levadas às últimas conseqüências por Ockham. A separação ainda mais clara entre os campos da filosofia e da teologia, e a afirmação de que a teologia não é uma ciência - pois não se fundamenta nem em uma intuição imediata nem na apreensão abstrata segundo as exigências do conceito - leva-o a afirmar que, nesta vida, nem intuímos a Deus, nem o apreendemos, tal como existe em si mesmo. ${ }^{31}$ Por isso, não podemos apresentar uma demonstração que leve ao assentimento incondicionado de sua existência, visto não existirem proposições referentes a Deus que gozem de evidência imediata, embora na aparência se possa pensar o contrário. ${ }^{32}$ Filosoficamente falando, portanto, "não se pode saber com evidência que Deus existe", ${ }^{33}$ como também não se pode demonstrar que não existe: podem-se apenas apresentar persuasiones, argumentos prováveis.

Esta posição, que a muitos pareceu saber a agnosticismo, em seu devido contexto possui inúmeros pontos de contato com o que foi dito por Tomás de Aquino e por Duns Scotus. Eles também concordam que não temos intuição direta de Deus e, por isso, não temos dele um conhecimento propter quid, e sim um conhecimento quia, que vai do efeito para a causa, e que, portanto, não permite apreender a causa em si mesma, e muito menos intuí-la em sua qüididade. Eles também concordam em afirmar que os dados da revelação pertencem a um nível de conhecimento que não é propriamente o da filosofia e, por isso, não se pode montar um argumento filosófico que conclua na revelação, pois então tratar-se-ia de uma conclusão que contém mais do que aquilo que se encontra nas premissas. Eles também negam qualquer argumento a priori para tratar da existência de Deus, como igualmente afimam que nossos conceitos sobre Deus não são conceitos próprios, mas comuns a ele e às criaturas.

${ }^{31}$ Quodl. V. q. 14. OTh, v. IX, p. 538. A respeito do problema da teologia racional em Ockham, cfr. 0 estudo e a bibliografia analisada em GHISALBERTI, A. Guilherme de Ockham. Porto Alegre, 1997, p. 131-160.

32

"Ista propositio quam nos habemus 'Deus est Deus', est dubitabilis, quia ista aequipollet isti 'ens summum et infinitum est ens summum et infinitum'. Hoc enim dicimus esse 'quid nomini' Dei, vel aliquid consimile. Et tamen ista in qua praedicatur idem de se, est dubitabilis, sicut unio illorum quae ponuntur a parte subiecti est dubitabilis; sicut si unio illorum esset falsa, total propositio esset falsa, propter falsam implicationem. Sicut si nullus homo esset albus, haec esset falsa "homo albus est homo albus'" (In II Sent. Prol., 2; OTh v. II, p. 112-113).

33 "Dico quod accipiendo Deum secundum primam descriptionem [quod Deus est aliquid nobilius et melius omni alio a se] non potest demonstrative probari quod tantum unus Deus est [...] quia non potest evidenter sciri quod Deus est, sic accipiendo" (Quodl I, q. 1, Oth, v. IX, p. 2). 
Talvez o mais intrigante para os leitores "cristãos" pouco conhecedores de Ockham, seja o crivo rigoroso e imperdoável a que submete toda a argumentação do passado, mostrando-lhe os pontos vulneráveis. Tanto as vias tomistas como a prova escotista, a seu ver, possuem sérias inconsistências, que as desqualificam, por concluírem dizendo mais do que o permitido pelas premissas. Parece-lhe, por exemplo, que a via da causa eficiente e a do movimento não concluem necessariamente na unicidade, nem a demonstram; nem se pode demonstrar que seja absurdo proceder ao infinito na série de causas eficientes. Segundo seu modo de ver, o argumento mais provável a respeito da existência de Deus é o que se elabora a partir das causas conservantes dos seres contingentes. E se pouco se pode dizer filosoficamente a respeito da existência e da essência divina, muito menos ainda se pode dizer de seus atributos, tais como a onipotência, a infinidade, a eternidade, o ser criador. Noutras palavras, a filosofia sabe de Deus aquilo que os filósofos pagãos, com tanto esforço, conseguiram formular a respeito dele. $\mathrm{O}$ mais é conhecimento de proveniência teológica.

Nesta questão, Ockham mostra toda a modernidade de sua posição, ao distinguir o que a filosofia pode dizer de Deus e o que ele disse de si mesmo. "A teologia racional elabora um discurso minimalista e imperfeito a respeito de Deus, um discurso limitado às possibilidades cognoscitivas do viajor, que por força de sua realidade deve ater-se ao nosso mundo atual, que é o único mundo do qual o homem pode falar em termos de evidência.". ${ }^{34}$

\section{Momento de continuidade: a pluralidade das formas.}

Em páginas de precisão e clareza, G. Fraile, resumindo estudos de diversos outros pesquisadores, observa que a aparente contraposição entre "agostinismo" e "aristotelismo", que obteve relativo sucesso há algumas décadas, precisa nuançar tanto o agostinismo como o aristotelismo, pois os pensadores medievais foram, sem exceção, tanto aristotélicos como agostinianos. ${ }^{35}$

Aceitando a observação, e considerando que os franciscanos foram geralmente classificados entre os agostinianos, convém anotar que o agostinismo da Idade Média foi, seguidamente, um conjunto um tanto heterogêneo de idéias, que nem sempre tinha a ver com santo Agostinho, e sim com Avicena, Maimônides e IonGabirol. Nos embates ideológicos entre 1260 e 1277, os teólogos conservadores, tendo à frente João Peckham, ao colocarem-se em defesa de um patrimônio que lhes parecia estar sendo atingido pelo assim chamado "averroísmo" da faculdade de artes e pela abertura dada por Tomás de Aquino às propostas aristotélicas, apelaram para Agostinho a fim de salvar o que julgavam ser o patrimônio da fé, e o Correctorium Fratis Thomae, de Guilherme de la Mare, atuou como o codificador deste ideário, ${ }^{36}$ 
dando uma certa homogeneidade ao grupo. ${ }^{37}$ Por isso, o agostinismo só será compreendido corretamente, se encarado como o apelo a teses filosóficas com a finalidade de defender o que parecia ser da essência da fé cristã. Quando, no final do século XIII, a Suma Teológica tornou-se leitura corrente e a crítica à iluminação divina se impôs, o apelo a Agostinho, a este nível, esvaiu-se.

A doutrina da pluralidade das formas substanciais, mais que agostiniana, é de fundo platônico-plotiniana, e foi desenvolvida por Avicena e Ibn-Gabirol, tendo chegado ao ocidente através de Gundissalino. Unidade ou pluralidade de formas no ser humano depende, inicialmente, de uma compreensão do que vem a ser a união da alma e do corpo para constituir o homem. Para Tomás de Aquino, alma e corpo são duas substâncias incompletas, ${ }^{38}$ destinadas uma para a outra, sem que tenham existência prévia, pois começam a existir quando da geração. Por encontrar-se o homem colocado no último grau dos seres espirituais, a alma humana, inferior aos espíritos puros, como os anjos, não pode realizar suas funções independentemente do corpo, e por isso a morte é algo violento contra a natureza do homem, e somente por graça divina a alma, separada do corpo, pode chegar a algum tipo de conhecimento antes da ressurreição. ${ }^{39}$ Para os franciscanos, pelo contrário, a alma é uma substância espiritual completa, do mesmo nível que os anjos. Ela possui subsistência espiritual independente do corpo, e tende para este não para aperfeiçoar-se, e sim para aperfeiçoar o corpo e, mais ainda, para a perfeição do conjunto. ${ }^{40}$ Embora admitindo que

37 FRAILE, G., op. cit. p. 685-688, apresenta as seguintes teses características do agostinismo: 1) confusão ou distinção insuficiente entre o campo da filosofia e o da teologia; 2) predomínio do bem sobre a verdade, do amor sobre o conhecimento; 3) desconfiança das provas "físicas" da existência de Deus; 4) exemplarismo; 5) criação do mundo no tempo; 6) tendência a identificar o ser e a luz; 7) hilemorfismo universal; 8) pluralismo das formas substanciais; 9) razöes seminais; 10) distinção substancial entre alma e corpo; 11) individualização em separado da alma e do corpo; 12) identidade da alma e suas potências; 13) iluminação especial divina para o conhecimento; 14) alma como imagem de Deus; 15) tendência ao fideísmo e ao misticismo. - Ora, estas características cabem muito bem ao pensamento de Boaventura, mas de nenhum modo o conjunto delas qualifica o pensamento de Olivi, Scotus e Ockham, que estão muito longe das de número 1, 4, 6, 9, 13 e 15.

"Non quaelibet substantia particularis est hypostasis vel persona, sed quae habet completam naturam speciei. Unde manus velpes non potest dici hypostasis vel persona, et similiter nec anima, cum sit pars speciei humanae" (ST I, q. 75, 4, ad 2). ST I, q. 89, a 1, in corp.

HONNEFELDER, L. (Ens inquantum ens. Münster, 2. ed. 1979. p. 68s) observa a respeito: "Por trás das concepções diferentes entre Tomás e Scotus, aqui apresentadas la respeito do primeiro objeto do intelecto], encontra-se uma antropologia com acentuação diferente. Para Tomás, a alma humana 'devido à determinação de sua natureza' encontra-se unida ao corpo. A separação entre alma e corpo, na morte, quando então esta unidade natural é supressa, é considerada como 'praeter rationem suae naturae' (cfr. ST I, q. 89, a. 1). Já para Scotus, a união da alma com o corpo não acontece 'nem por causa do aperfeiçoamento do corpo, nem somente por causa do aperfeiçoamento da alma, mas por causa do aperfeiçoamento do todo resultante de ambos'. Nenhuma das duas partes deste todo recebe, só por sí, através da união, uma perfeição, que não teria também sem a uniăo. Contudo, a união, como determinada para o fim da perfeição do todo, é algo que faz sentido (cfr. Ord. IV, d. 45 , q. 2, n. 14. Ed. Vivès, XX, 305s.). A alma possui, sem dúvida, uma inclinação natural de comunicar ao corpo a própria perfeição e, neste sentido, encontra-se ordenada para o corpo; contudo, como se trata de uma inclinação natural para um ato segundo, a suspensão desta inclinação, tal como acontece na morte, não representa uma violência nem uma imperfeição para a alma em seu ato primeiro. A alma permanece em seu próprio ser em qualquer estado de igual perfeição (cfr. Ord. IV, d. 43, q. 2, n. 24-25. Ed. Vivès, XX, p. 54s.). Por isso, ela possui, também quando separada do 
ela seja enteléquia do corpo, afirmam eles que esta não é sua função essencial, pois primeiramente ela é uma substância espiritual que subsiste por si mesma. ${ }^{41}$

Dentro desta leitura, foi fácil a Boaventura formular uma doutrina na qual a multiplicidade de formas no homem encaixa-se logicamente. ${ }^{42}$ Vendo o corpo como uma substância completa, não pode admitir que a forma elementaris do corpo se possa unir à alma sem a mediação da forma mixtionis, e esta sem a forma complexionis, sendo que só então ele está apto a receber a vida. ${ }^{43}$

Com Peckham, a teoria é defendida em vista de implicações de caráter teológico, como a de explicar a identidade do corpo de Cristo no túmulo. Tanto o corpo como a alma são vistos como compostos, nos quais uma série de formas se fazem presentes. O corpo possui inicialmente uma forma corporeitatis (expressão que se transmitirá aos pósteros), que está presente tanto no corpo vivo, como no morto. A ela, segue-se a forma mixionis, que o dispõe para a união com a alma. Esta, de sua parte, possui tantas formas quantas são as perfeições e as atividades que exerce, estando cada uma delas disposta a receber a forma superior. ${ }^{44}$ Não é muito diferente a posição de Rogério Marston, Mateus de Acquasparta e Ricardo de Mediavilla. Guilherme de Ware é dos poucos que se inclinam para a unidade da forma.

Pedro João Olivi faz um balanço das correntes de seu tempo, a fim de montar sua própria teoria. Na trilha de Boaventura, afirma que a forma dá à matéria a atualidade formal, mas não toda a atualidade de que esta é capaz e, por isso, à matéria-prima continua sendo aquilo que é por natureza: a potência de receber todas as formas que a possam aperfeiçoar. Uma forma não esgota, portanto, as potencialidades intrínsecas de perfeição da matéria. Com este arrazoado metafísico está aberto o caminho para a demonstração de que no homem existem outras formas substanciais. Mas o modo de existir de tais formas no homem não pode ser nem o de subordinação, nem o de justaposição. A unidade do ser e a pluralidade das formas só se mantêm se entre elas se estabelecer um vínculo ontológico de dependência, de tal modo que a forma superior venha teleologicamente a aperfeiçoar, mas não elimine, as formas inferiores. ${ }^{45}$

corpo, a capacidade de conhecer o desconhecido, tanto de modo abstrativo, como de modo intuitivo, com a condição de que aquilo que será conhecido lhe esteja presente (ibid. d. 45, q. 2, n. 12. Ed. Vivès, XX, p. 304s.).

41 Do mesmo mod̃o, o corpo também é uma substância completa em si mesmo. Isto levaria a um estudo sobre a noção filosófica de matéria e seria possível abrir um parágrafo dedicado ao tema do modo como a escola franciscana, opondo-se à noção aristotélico-tomista, desenvolve uma noção de matéria à qual atribui um modo real de existência antes de ser informada, pois, se fosse pura potência, sem sequer possuir o ato de existir, então seria não-ser. [Após a redação do presente texto surgiu um clássico sobre o tema: o livro de A. Pérez-Estévez. La matéria - de Avicena a la Escuela Franciscana (Maracaibo, 1998). Nele apresenta-se o pensamento de Boaventura, J. Peckham, R. Marston, P. J. Olivi, R. de Mediavilla, e Duns Scotus a respeito da matéria]. 
Fiel à linha traçada por seus confrades, também Duns Scotus afasta-se da teoria da forma única no ser humano. Seu ensinamento a respeito é complexo, encontrando-se imbricado com outros temas, de tal modo que é necessário relacioná-lo com as formalitates, com a haecceitas e mesmo com a ultima solitudo, ${ }^{46}$ a fim de compreendê-lo em toda sua amplitude. Concordando com Aristóteles e Tomás, admite que a alma intelectiva está unida substancialmente ao corpo, do qual é a forma. Contudo, seguindo a tradição da ordem, afirma que esta forma não é, nem pode ser, o término intrínseco da matéria, ${ }^{47}$ da qual não esgota todas as possibilidades. Ou melhor: como, segundo sua doutrina, tanto o corpo como a alma são duas substâncias completas, a forma de corporeidade que precede a união entre corpo e alma não deixa de existir ao surgir a união. Esta união substancial cria uma unidade, mas é uma unidade diferente das duas outras que preexistiam, a do corpo e a da alma. Em tal união, a forma corporeitatis toma-se latente, mas não desaparece, enquanto a forma da alma intelectiva subsiste unida à matéria; ela se distingue da alma intelectiva apenas potencialmente, como princípio de realidade, mas continua operante na unidade, na qual as outras formas anteriores, como a vegetativa e a sensitiva existem só como formalitates, por serem absorvidas de todo pela forma racional. ${ }^{48}$ Isto significa que a vegetativa e a sensitiva diferenciam-se da intelectiva dentro da unidade, o que, para Scotus, é algo que se explica pela distinctio formalis a parte rei - a distinção formal por parte da coisa. Já a forma corporeitatis permanece de outra maneira. "A unidade da forma se dissemina pela pluralidade das formalidades e pressupõe, latente, uma potencial forma corpórea" ${ }^{49}$ De fato, pode-se facilmente explicar como a alma racional assume tudo o que pertence anteriormente à alma vegetativa e à sensitiva, mas não se explica como, no final de todo o dano maior que se possa infligir a um vivente, se tenha sempre como resultado um cadáver. ${ }^{50}$ Isto

46 RIGOBELLO, A. "La nozione di corporeità in Duns Scoto". In: Comissio Scotista Internationalis (ed.) Homo et mundus. Roma, 1984, p. 345-353. Cfr. STELLA, P. T. "La teoria ilemorfica nel sistema scotista". In: Commisio Scotistica Intemationalis (ed.) De doctrina Iohannis Duns Scoti. vol. II. Roma, 1968, p. 241-295. Trata-se de um dos poucos trabalhos em que o problema é colocado em seu contexto, baseando-se em farta citação de textos scotistas.

47 "De anima intellectiva manifestum est quod ipsa non est nec esse potest terminus intrinsecus materiae, nec materia ad illum gradum proficere potest" (Ord II, d. 12, q. un. Ed. Vivès, v. XII, p. 547).

48 "Non est ponenda pluralitas sine necessitate. Nihil autem cogit ponere pluralitatem elementorum vel formarum substantialium in mixto, quia non operatio [...], nec trasmutation (Ord. II, d. 15, q. un. n. 5. Ed. Vivès, XIII, p. 11). "Dico ergo quod elementa non manent in mixto secundum substantiam. $\mathrm{Nec}$ oportet dicere quod maneant secundum qualitates suas, sicut nec qualitates extremae manent in medio. Manent ergo in mixto sicut si diceretur quod sensitiva et vegetativa manent in intellectiva" (ibid., p. 17). RIGOBELLO, A. op. cit., p. 346.

"Non potest regulariter esse idem effectus a quibuscumque et quantumcumque diversis agentibus. Sed a quocumque et qualitercumque corrumpatur corpus vivum, dum tamen non statim resolvatur in elementa, semper producitur cadaver idem et eiusdem rationis. Patet ad sensum. Sed idem non potest esse terminus proprius actionis hius et illius agentis. Igitur non est novum productum per actionem corruptivam ipsius animati, sed est derelictum [...]. Si bos per cultellum vel submersionem et interfectionem vel aliis modis corrumpatur, semper derelinquitur idem cadaver et eiusdem rationis" (Ord. IV, d. 11, q. 3, n. 38. Ed. Vivès, XVII, p. 415). "Forma animae non manente, corpus manet; et ideo universaliter in quodam animato necesse est ponere illam formam qua corpus est corpus, aliam ab illa qua est animatum" (Ibid. d. 2, q. 3, n. 54). 
quer dizer que, quando a alma intelectiva, forma substancial do sinolo - do conjunto alma e corpo - cumpre sua missão e deixa o corpo, para o qual, segundo Scotus, não foi necessariamente determinada, pois é uma substância completa em si mesma, então a forma corporeitas latente volta a assumir sua função, o que permite que se diga de um cadáver, que se trata do cadáver de um amigo, ou de um conhecido, e não simplesmente de um amontoado de elementos, de cuja procedência anterior nada se sabe. Como isso, porém, salva-se também uma verdade da fé: a forma corporeitas latente em Cristo permite dizer que o corpo morto, que foi sepultado, é idêntico ao corpo que depois ressuscitou.

Ockham retoma Scotus e também defende a pluralidade de formas no homem, embora observe que esta afirmação não possui um caráter apoditico, pois não é demonstrada por proposições evidentes. Segundo ele, para quem a alma intelectiva é a forma do corpo, há no homem outras duas formas: a alma sensitiva e forma de corporeidade. Isto se demonstra porque a experiência humana mostra que o corpo é corruptível e, como tal, não pode ser informado diretamente por uma forma incorruptível, mas sim por uma forma sensitiva que se estende por todo o corpo e que desaparece com a morte. Que tal forma existe, parece claro devido ao fato de que o homem é capaz de desejar uma coisa com o apetite sensitivo e recusá-la com a vontade racional. ${ }^{51}$ Do mesmo modo, também a forma de corporeidade é atestada pela experiência, conforme Scotus já havia manifestado, tanto pelo fato de que somos capazes de identificar de quem é o cadáver com que nos deparamos, como pela necessidade teológica e lógica de poder explicar a unidade do corpo vivo e do corpo morto de Cristo.

\section{Outro momento de continuidade: o indivíduo}

Se há tema qualificável como tipicamente franciscano, e no qual podem ser registrados os avanços e recuos na formulação, é sem dúvida o do conhecimento intelectual do singular captável pelos sentidos. ${ }^{52}$

A questão é tão antiga como a grande Filosofia. ${ }^{53}$ Inicia-se com Platão, que concede o primado ao universal, por constituir o ser verdadeiro, enquanto o particular é cópia imperfeita. Segue-se com Aristóteles, que recusa o mundo das idéias de Platão, mas afirma que o verdadeiro conhecimento é o do universal, por ser intelectual, havendo do singular apenas um conhecimento a nível sensitivo.

51 "Impossibile est quod in eodem obiecto sint simul contraria: sed actus appetendi aliquid et evitandi sive renuendi idem in eodem subiecto sunt contraria. Ergo si sunt in rerum natura, sunt in diversis subiectis; sed manifestum est quod sunt simul in homine: quia id idem quod homo appetit per appetitum, renuit per intellectum" (Quodl. II, q. 10; Oth IX, p. 57; cfr. GHISALBERTI, A., op. cit., p. 52 214s; MERINO, J. A., op. cit., p. 349ss.).

52 Cf. a respeito o trabalho magistral de C. Bérubé. La connaissance de l'individuel au moyen age. Montréal/Paris, 1964. Desta obra, conforme indicado, foram tomadas inúmeras das citações a se-

53 guir.

Cf. a respeito H. Heimsoeth. Die sechs grossen Themen der Abendländischen Methaphysik und der Ausgang des Mittelalters. Darmstadt, 6. ed. 1974, p. 172-203. 
Entre os medievais, a questão montou-se sobre dois pilares. De um lado, a teoria aristotélica do conhecimento, conforme elaborada no De anima e como a entenderam os grandes comentadores árabes e todos os pensadores até a metade do século XIII: o conhecimento intelectivo que temos, ao abstrair da materialidade, é sempre um conhecimento do universal De outro lado, um problema teológico de graves consequiências: Deus, os anjos e as almas separadas possuem conhecimento das coisas individuais ou também a respeito deles deve ser dito que só conhecem no universal? E mais ainda: se o conhecimento humano só pode ser no universal, é possível então que no céu o homem possa conhecer a Deus?

Roberto Grosseteste, João de la Rochelle, Alexandre de Hales, Boaventura e João Peckham, cada um a seu modo, reservaram para o conhecimento intelectual tão somente o universal. $\mathrm{O}$ argumento para tanto, tomado de Aristóteles, via Avicena e Averróis, é o de que a potência intelectiva apreende a forma despojada de toda matéria. Ora, como a matéria individua a forma, ao ser esta captada sem a materialidade, é logicamente captada também sem a individualidade. A pergunta que era necessário obviar, para todos eles, permanecia sempre a mesma: Deus e os anjos, que são puros espíritos, e as almas separadas dos corpos, podem eles conhecer o singular material enquanto tal? A resposta de todos, com diversas variações, era afirmativa, sob a alegação de que o intelecto humano inicia pela percepção sensível, enquanto Deus, os anjos e as almas separadas, que não possuem sentidos, percebem o objeto diretamente.

Neste universo, foi uma verdadeira revolução a teoria de Tomás de Aquino, dizendo que o homem não possui uma intelecção direta do singular, mas por uma reductio ad phantasmata pode conhecê-lo indiretamente. ${ }^{54}$ As críticas de Síger de Brabante mostram o impacto que esta afirmação, baseada em Aristóteles, causou no aristotelismo ortodoxo.

Coube a Rogério Bacon, por primeiro, em textos provavelmente anteriores a 1250, iniciar o longo caminho em favor do conhecimento direto do singular por parte do homem. Caminho longo, sem dúvida, porque as teorias aristotélicas, de que todos estavam imbuídos, não podiam servir como suporte, exigindo-se, por isso, que aos poucos, tateando, com avanços e recuos, se fosse elaborando uma nova teoria.

Partindo da divisão aviceniana da natureza em universal e particular, Bacon conclui que na ordem da intenção o individual, que é substância primeira, antecede o universal - o que se comprova pela teologia, pois "Deus não criou este mundo por causa do homem universal, mas por causa das pessoas singulares; como também não criou e remiu o homem universal, mas as pessoas singulares; e nem a glória do céu está preparada principalmente para o homem universal, mas para as pessoas eleitas, numericamente contadas". 55 Embora em Bacon a teoria esteja

${ }_{55}^{54}$ STh I, q. 85, a. 1 , in corp.

55 "Et quia omnia quae tracto sunt propter theologiam, patet per rationes theologicas quod universale non habet comparationem cum singularia. Non enim Deus fecit hunc mundum propter universalem hominem, sed propter personas singulares; nec creavit humanum genus, nec redemit propter 
apenas se delineando e haja nele uma certa ingenuidade no manuseio de texto como quando fala da existência de espécies particulares e universais tanto nas coisas como no intelecto - este passo inicial permite-lhe inverter a questão que até então se impunha: não se pergunta mais 'estultamente' qual é a causa da individuação, e sim qual é a causa da universalização, visto que nem o indivíduo, nem algo a ele acrescentado produz 0 universal. ${ }^{56}$

A argumentação baconiana a partir da Teologia e o primado do individual baseado na evidência incorporaram-se à tradição da ordem franciscana e ressoarão com todo vigor no final da jornada, pela voz de Guilherme de Ockham.

Com Mateus de Acquasparta, entre 1275 e 1279, mais um passo é dado, elevando-se a pergunta a respeito do conhecimento do singular material ao primeiro plano de debates acadêmicos, merecendo mesmo uma questão disputada. Mateus distingue entre o fato e o modo do conhecimento: o fato, que toma por evidente, pertence ao domínio da Teologia; o modo, motivo de questionamentos, ao da Filosofia. Para ele, ao contrário do que fora proposto até então, o intelecto conhece os singulares de modo direto e próprio, e não por acidente. A espécie singular chega ao intelecto por primeiro e é dela que o intelecto abstrai a intenção universal. Ora, a espécie universal é suficiente para que se tenha uma idéia do homem em geral, mas não para se conhecer o particular. Para conhecer o singular enquanto existente, a espécie singular deve manter o contato como exterior e ser levada ao intelecto pelo sentido, juntamente com a de lugar e de sensação. ${ }^{57}$ Para tanto, a alma não sofre a ação das coisas corporais, antes, a partir delas forma espécies proporcionais aos órgãos, até àquele que lhe permite formar um ser inteligivel, para ser então recebido no intelecto possivel.

Pedro João Olivi, na análise de C. Bérubé - citando E. Bettoni - é o único pensador do século XIII que corta todos os laços com a leitura aristotélica do conhecimento, elaborando uma teoria que não se permite jamais cair na tentação de assumir elementos aristotélicos ou agostinianos tradicionais que com ela não concordem. Para tanto redefine a função do objeto no conhecimento, limitando a ação

hominem universalem sed propter personas singulares; nec gloria est parata principaliter homini universali, sed electis personis et certis in numero. Manifestum est igitur, quod singulare sine comparatione est melius quam universale" (R. Bacon. Liber I Communium naturalium, ed. R. Steele, c 7, p. 95; apud Bérubé, p. 72).

56 "Et cum quaerunt quid erit causa individuationis, si nec species nec aliquid additum speciei causat eam, quaerendum est primo ab eis quid est causa universalitatis, si nec individuum nec aliquid ad7itum ad ipsum faciat universale" (ibid. p. 95; Bérubé, p. 73).

" $\mid . .$.$] intellectus cognoscit et intelligit singularia per se et proprie, non per accidens, ita quod singu-$ laria cognoscit per species singulares, universalia per species universales, nec species universalis sufficit ad cognoscendum singularia, et fortassis, licet prius in habitu cognoscat hominem universalem [...], tamen prius actu cognoscit hunc hominem prius enim defertur species singularis ad intellectum et ex illa colligit intentionem universalem, quam ipsum universalem intelligat [...]. Sed ad hoc, quod cognoscat et intelligat hunc hominem, necesse est quod hujus hominis singularis fiat apud intellectum, ita quod, quot homines vel quot cognoscit singularia, tot species habet differentium singularium [...]. Sed illud idem singulare non potest cognoscere esse, ut scilicet ipsum intueatur vl speculetur, nisi per sensus, quisbus mediantibus defertur species ejus, loci et actus usque ad intellectum, in qua intueatur ipsum" (M. de Acquasparta. Quaestiones disputatae selecta, De cognitione. q. IV, p. 309 s.; Quaracchi, 1903; apud Bérubé, p. 97). 
deste à causa terminativa. ${ }^{58}$ Depois, critica a posição clássica, para a qual o intelecto não possui como objeto direto e imediato nada a não ser o universal, não the sendo possível conhecer diretamente o singular. Ora, diz ele, o ato cognitivo de um objeto individual tem como término este mesmo objeto, enquanto individual, não havendo lugar, por inúteis, para as espécies sensiveis e inteligíveis, ${ }^{59}$ ou para 0 intelecto agente..$^{60}$ No ato intelectivo, o que existe são duas propriedades opostas: por um lado, é algo que procede de um princípio interno ativo de quem conhece e que, por isso, tem consciência de que se trata de uma ação que se volta para um objeto; de outro, enquanto procede terminativamente do objeto, parece uma paixão recebida do objeto e que penetra na faculdade intelectiva. Além disso, a colligantia, a relação íntima entre as faculdades vegetativa, sensitiva e racional, faz com que qualquer mudança em uma delas seja percebida também nas demais. Por isso, a modificação na faculdade sensitiva é percebida pela intelectiva, sem que seja preciso recorrer ao aparato da abstração. Este é o ato primeiro do conhecimento; o universal é um ato segundo, existente tão somente no intelecto, sem um contraponto na realidade: é o resultado de um processo seletivo sobre o objeto individual, mas ao qual não corresponde nenhuma espécie universal, pois se esta existisse, deveria existir também um objeto universal correspondente, o que é um absurdo para toda a sã razão, visto que entre os seres criados não pode existir uma universalidade real.

Na década de 1290, enfim, Vital de Four (depois elevado ao cardinalato, tal como já o fora antes Mateus de Acquasparta) acrescenta uma última contribuição importante ao tema. Ele afirma que o termo singular, tão usado nos debates, é tomado sob duas acepções, significando, por um lado, o indivíduo enquanto existente e, de outro, a individualidade, enquanto diferença de um para outro. ${ }^{61}$ Ora, observa o autor, o homem não conhece o singular em sua singularidade (não é capaz de distinguir entre dois objetos perfeitamente semelhantes), mas o conhece enquanto existente. Não conhece um ser, enquanto tal, em sua essência distinta da de outro ser, mas o conhece individualmente enquanto existente. Trata-se de um conhecimento direto, sem a reductio ad phantasmata, ou a algo semelhante, embora afirme - contra Olivi - que este conhecimento, tal como o universal, se

58

59

60

61. Ibid. apêndice, q. 2, p. 504-513.

${ }^{61}$ "Circa secundum principale, quod scilicet intellectus conjunctus corpori intelligit singulare, primo est sciendum quod singulare duobus modis accipitur: primo modo ut dicit actualem rei existentiam; [...] alio modo secundum quod singulare dicit gradum distinctum naturalem unius individui a gradu naturae alterius individui ejusdem speciei" (F. Delorme. "Le cardinal Vital de Four". In: AHDMA, 2 1927, p. 163; apud Bérubé, p. 113). 
realiza através de espécies. O sentido chega ao conhecimento de forma orgânica, pela impressão do objeto nele; já o intelecto não conhece desta maneira: ele apreende a realidade no sentido, não pelo sentido, pois há uma presença ativa do intelecto no ato de conhecer. Assim, a ação dele é perfectiva da ação sensivel, sendo que do sentido e do intelecto resulta uma única ação cognitiva, tal como da virtude da semente e do calor do sol também resulta um só desabrochar da nova vida vegetal. ${ }^{62}$ Separado do conhecimento dos sentidos, o intelecto pode atingir tão somente o conhecimento universal, sem a possibilidade de formar o juízo de existência sobre o singular.

No decorrer da segunda metade do século XIII desenvolveu-se, portanto, dentro da ordem franciscana, uma teoria do conhecimento do singular que pode ser resumida em quatro momentos: 1. Rogério Bacon, por primeiro, afirma a precedência do singular, afirmando que Deus cria seres singulares e não universais; 2 . Mateus de Acquasparta diz que o intelecto conhece os singulares de modo direto e próprio, e não por acidente. A espécie singular chega ao intelecto por primeiro e é dela que 0 intelecto abstrai a intenção universal; 3. Pedro João Olivi afasta-se definitivamente do aristotelismo, negando as espécies e o intelecto agente, e afirmando o conhecimento direto do singular, relegando o universal para algo existente apenas no intelecto; 4. Vital de Four, enfim, distingue entre o conhecimento da singularidade (que motivava as longas discussões a respeito do princípio de individuação) e o conhecimento do singular enquanto existente.

Analisada neste contexto, a posição de Duns Scotus, no início do século XIV, apresenta-se como conservadora. Ele, que conhecia muito bem o pensamento de seus confrades, não os acompanha ao longo de todo o percurso. Concorda com eles, ao dizer que o intelecto é capaz de conhecer o singular, mas não discorda de Tomás de Aquino, quando diz que nesta vida só nos é possível conhecer diretamente o universal. ${ }^{63}$ Sua posição resume-se, pois, em afirmar, por um lado, que o singular é cognoscivel em si mesmo, pois a singularidade nada acrescenta à universalidade, a não ser o último grau de atualidade. ${ }^{64}$ Por isso, assim como o universal pode ser conhecido, também o singular o pode. Por outro lado, contudo, constatamos que nosso conhecimento dos indivíduos não se dá porque deles conhecemos a essência, e sim porque lhes conhecemos os acidentes que distinguem

${ }_{63}$ Ibid., p. 168; Bérubé, p. 116.

Scotus - é bem recordar que foi o mais teólogo entre os medievais - não dedica questão alguma, nem disputada, nem ordinária, ao conhecimento do singular; analisa contudo o problema nas Questões sobre a Metafísica (livro 7, q. 14-15; OPh IV, Saint Bonaventure, 1997, p. 280-309). Diversos textos a respeito encontram-se ao tratar do objeto primeiro do conhecimento. Cf. L. A. De Boni. "Como alguém que vê à luz de vela". In: id. (org.) Finitude e transcendência -Festschrift em homenagem a Emildo Stein. Porto Alegre/Petrópolis, 1995, p. 388-403.

"Intelligibilitas absolute sequitur entitatem [...]. Singulare totam entitatem quiditativam superionum includit, et ultra hoc, gradum ultimae actualitatis et unitatis [...], quae unitas non diminuit, sed addit ad entitatem et unitatem, et ita ad intelligibilitatem. [..] singulare nihil includit quod non incluit universale nisi gradum praedictum. Sed non excluditur ab ipso intelligibilitas ratione alicuius inclusi in universali, quia tunc universale non esset per se intelligibile" (Quaestiones in Metaphysicam, 1. 7, q. 15, n. $14-15$; p. 298 ). 
um de outro, tanto é que não somos capazes de distinguir entre dois objetos muitos semelhantes. ${ }^{65}$ Por isso, nesta vida não podemos conhecer diretamente o singular. De forma indireta, porém, o intelecto é capaz de compor em um conceito único os diversos dados do conhecimento sensivel anteriormente universalizados, de modo a formar um conceito confuso sobre o singular, baseado no conjunto de suas notas individuantes. ${ }^{66}$

Como se vê, na questão do conhecimento do singular, Scotus não segue todos os passos de seus antecessores. Sua posição, afirmando um conhecimento indireto e confuso, está mais próxima da de Tomás de Aquino que da de seus confrades, algo que não passou despercebidos aos scotistas posteriores. Neste sentido, parece-me que convém relativizar em parte o juízo de $\mathrm{H}$. Heimsoeth, quando toma Duns Scotus como o autor da grande virada metafísica do universal para o individual. ${ }^{67}$ Sem negar-lhe os méritos, cabe observar que Olivi, antes dele, e Ockham, após ele, haveriam de desenvolver mais decididamente uma metafísica do singular.

Mérito scotista, pelo contrário, é sua teoria da intuição, a qual, aqui, acaba sendo apenas mencionada. Por ela afirma o primado do conhecimento intuitivo sobre $\mathrm{o}$ abstrativo e, abandonando o arcabouço aristotélico das espécies, admite 0 conhecimento imediato do singular existente. ${ }^{68}$

Não é preciso dizer que também nesta questão, e principalmente nela, Ockham é o ponto de chegada da escola franciscana. É possível mesmo estudarlhe toda a obra a partir da noção de primado do individual sobre o universal no plano lógico, gnoseológico e metafísico. De uma forma ou de outra, os textos que se seguem tratam deste tema, para o qual, aliás, volta-se 0 interesse de muitos pesquisadores recentes. $^{69}$

Ibid., n. 20; p. 301.

Ibid., n. 32; p. $305 \mathrm{~s}$.

"Erst mit Duns Scotus kommt eine grosse Wendung in die ganze Frage [...]. Duns Scotus nun führt ein Formprinzip auch für das Individuelle ein!" (op. cit. p. 181).

Cf. C. Bérubé. op. cit., p. 176-233, com indicação da principal bibliografia então existente (p. 176 s).

69 Cf., entre outros, P. Alféri. Guillaume d'Ockham. Le singulier. Paris, 1989. C. Pannacio. Les mots, les concepts et les choses. La sémantique de Guillaume d'Occam et le nominalisme d'aujoud'hui. Paris, 1991. C. Michon. Nominalisme. La théorie de la signification d'Occam. Paris, 1994. P. V. Spade (org.) The Cambridge Companion to Ockham. Cambridge, 1999. 